\title{
Sobre o cuidado na saúde: da assistência ao cidadão à autonomia de um sujeito
}

\author{
Ana Cláudia Barbosa da Silva Roosli* (i) \\ Claudia Maria de Sousa Palma $\odot$ \\ Maria Lúcia Mantovanelli Ortolan
}

Universidade Estadual de Londrina. Londrina, PR, Brasil

\begin{abstract}
Resumo: Este artigo discute a categoria do cuidado nas ações de saúde na atenção básica, interrogando a predominância de uma oferta e de uma demanda na via assistencial-universalizante. Como resposta, marca a relevância da psicanálise a um cuidado que ultrapassa o cidadão que espera por um serviço de direito, apontando para o direito pelo cuidado ao sujeito na sua singularidade. Acrescentam-se a essa perspectiva os benefícios do campo da psicologia do trabalho, em que a conquista e o fortalecimento da saúde dos próprios trabalhadores se inscrevem como necessidades à sustentabilidade de uma oferta de cuidado para além da aplicação de protocolos normatizadores. Nessa via, a inclusão da psicanálise e da psicologia do trabalho vem somar no exercício do cuidado na saúde, ampliando as perspectivas de atuação dos psicólogos vinculados à atenção básica, ultrapassando o nível de oferta assistencial.
\end{abstract}

Palavras-chave:psicologia na saúde, psicanálise, cuidado em saúde, atividade de trabalho, saúde dos trabalhadores.

\section{A categoria do cuidado à saúde e as políticas públicas de saúde}

As reflexões presentes neste artigo se originaram de interrogações de psicólogas (duas docentes e supervisoras, e uma em formação de residência) inseridas numa Residência Multiprofissional em Saúde da Família (RMSF). Neste cenário nos interessa discutir a categoria do cuidado no contexto da saúde pública, a partir de uma argumentação que inclui dois aspectos pouco considerados, porém inerentes ao processo saúde-doença: a singularidade resultante das incidências pulsionais e o necessário fortalecimento da saúde dos trabalhadores, tópicos que problematizamos como fundamentais a uma assistência rumo ao protagonismo dos usuários. Para tanto, iniciamos com alguns pontos sobre a consolidação da saúde pública no Brasil e suas diretrizes assistenciais, situando a importância adquirida pela categoria cuidado na assistência à saúde no Brasil.

No período colonial, muito pouco se fez para a saúde da população (Ramos \& Netto, 2017). Com a vinda da família real ao Brasil criam-se as primeiras instâncias de saúde pública (Fisicatura-mor e Provedoria-mor de Saúde), as quais privilegiavam os nobres e integrantes do clero, ou seja, a maior parte da população se dirigia à Santa Casa de Misericórdia, gerenciada pela Igreja e com péssimas condições de infraestrutura (Escorel \& Teixeira, 2012). De modo geral, o que se entendia por saúde pública, antes da consolidação da República, caracterizava-se

\footnotetext{
* Endereço para correspondência: anaclaudia79@uel.br
}

pelas atividades da polícia sanitária e da Inspetoria de Saúde dos Portos, que realizava a fiscalização sanitária dos portos marítimos (Ramos \& Netto, 2017).

Com efeito, o ponto histórico essencial para os objetivos deste trabalho tem início nos anos 1920, quando surgem as Caixas de Aposentadoria e Pensões (CAPs), financiadas pela União, por empresas e empregados (Bravo, 2008), com fins de proteção na velhice e na doença. Foi o primeiro esboço de um sistema previdenciário e, a partir de então, forma-se um modelo de proteção social do tipo seguro social, de origem bismarckiana (Lobato \& Giovanella, 2012). É com a criação do Ministério da Saúde (MS), em 1953, que o Estado se empenha em garantir o acesso à saúde da população rural, enquanto, na zona urbana, saúde ainda era privilégio de trabalhadores de carteira assinada e seus familiares. Como apontado por Asensi (2013), a época varguista não conseguiu superar o sentido social da saúde enquanto caridade: saúde era direito trabalhista ou serviço privado.

Durante o governo de Juscelino Kubitschek (1956-1961), os investimentos na saúde pública continuaram em segundo plano, tendo "uma nova configuração dos serviços médicos de saúde privados, através do crescimento da medicina de grupo, que funcionou como um dos pilares para a implementação das políticas neoliberais no âmbito do setor saúde na atualidade" (Ramos \& Netto, 2017, p. 49). Com a instauração da ditadura militar em 1964, a atenção médica privatizante é privilegiada em detrimento do setor público e do tratamento da saúde como questão coletiva (Bertolozzi $\&$ Greco, 1996). Nessa época, delineou-se uma saúde pública de "natureza preventiva e as atividades 
epidemiológicas e de vigilância sanitária . . . e as atividades de cunho assistencialista - e não contributivo - permaneciam sendo prestadas pelas instituições de caridade" (Ramos \& Netto, 2017, p. 51).

A consolidação e a permanência de um sistema de saúde desigual geraram insatisfação e questionamentos de diversos atores da sociedade - usuários, trabalhadores, acadêmicos, entre outros -, o que culminou no Movimento da Reforma Sanitária Brasileira e na $8^{\text {a }}$ Conferência Nacional de Saúde (CNS), pautada na "contribuição e a influência do movimento sanitário e da Reforma Sanitária para o novo sistema normativo de saúde" (Ramos \& Netto, 2017, p. 53). Dessa conferência resulta o capítulo sobre saúde da Constituição de 1988, o qual sistematiza a criação do Sistema Único de Saúde (SUS) e estabelece o princípio de um sistema de saúde gratuito e de qualidade para todos.

A partir da criação do SUS, os avanços foram inegáveis, mas desafios e dificuldades ainda persistem, na medida em que alterações constitucionais, após 1988, recolocam a saúde na perspectiva de um "tratamento secundário atribuído ao financiamento do SUS, o que compromete seu funcionamento" (Ramos \& Netto, 2017, p. 63). Movimentos importantes foram feitos para priorizar a qualificação, a humanização e o acesso aos atendimentos, principalmente na atenção básica (AB). Depois de 1995, houve a expansão de cobertura nesse nível de assistência, impulsionada pelo MS, com a criação de programas importantes, como: Programa Saúde da Família (PSF), Projeto de Profissionalização dos Trabalhadores da Área de Enfermagem (Profae) e a Rede de Escolas Técnicas do Sistema Único de Saúde (RET-SUS). Uma vez que o SUS assume a AB como porta de entrada, estratégias de fortalecimento como estas se mostram essenciais (Marques \& Mendes, 2003).

Dessa forma, a evolução das políticas públicas de saúde sempre esteve relacionada à evolução políticosocial e econômica do país sob uma ótica estritamente capitalista. Como apontado por Asensi (2013), as relações de poder e de patrimonialismo caracterizaram a saúde como um favor exercido pelo governo à população. Nesse sentido, no contexto histórico da construção das políticas de saúde pública, manteve-se a dualidade entre medicina preventiva, enquanto abordagem biologizante no controle das epidemias, e curativa, focada na supressão de patologias associadas às "dificuldades na implantação da integralidade e déficits na formação das equipes e nas condições e relações de trabalho" (Fertonani, Pires, Biff, \& Scherer, 2015, p. 1869).

A partir de 1994, a superação desse modelo é impulsionada pela implementação da Estratégia Saúde da Família (ESF). Como eixo norteador e reorganizador do sistema de saúde por meio da Atenção Primária à Saúde (APS), essa proposta determina que as ações de saúde na $\mathrm{AB}$ devam ser enfáticas na produção de saúde, e não na cura da doença (Scherer \& Menezes, 2016). Fertonani et al. (2015) sublinham que, no nível primário de atenção à saúde, a categoria do cuidado congrega uma ênfase na produção de saúde e autonomia do sujeito. Assim nos parece pertinente localizar o surgimento histórico da categoria do cuidado na saúde, a fim de problematizar a adoção dessa perspectiva da assistência à saúde na $\mathrm{AB}$.

No período do Renascimento, entre os séculos XIV e XVI, quando ocorre uma ruptura paradigmática e o advento de novas formas de saber e, consequentemente, de cuidar, inscreve-se um cuidado sob o surgimento da racionalidade científica, instaurando-se clínicas e hospitais (Nardi \& Ramminger, 2012). Todavia esse cuidado não se colocava enquanto atividade de trabalho, e apenas a figura do médico prevalecia, sendo ele o gestor dos hospitais: nasce a biopolítica, da qual, segundo Marta e Teixeira (2016), são representantes "o corpo médico e seus agentes .... Não é mais sobre a alma que se assenta a base das prescrições sobre o cuidado, mas sobre o corpo da medicina dos órgãos, fragmentado e mecanicista" (p. 4754). O sujeito passa a ser apenas um objeto das intervenções médicas (Nardi \& Ramminger, 2012) e o cuidado assume o sentido de restauração das funções perdidas do corpo.

A genealogia do cuidado estudada por Foucault (1969/2002) e a problematização do cuidado em saúde enfatizam o nível terciário de atenção, isto é, hospitais e modelos curativos, analisando o cuidado à saúde em uma perspectiva que identifica as relações de poder que operam nos serviços e nas ações de saúde, o que o autor denominou de biopoder. Atuante no nível disciplinar, tal perspectiva concebe o corpo como máquina e demarca a associação do cuidado ao controle. Abordar o cuidado sob essa perspectiva remete a quanto esse poder está ativo na produção de modos de vida, saúde, doença e subjetivação no cotidiano da assistência à saúde (Álvarez \& García, 2011), inclusive concedendo ao cuidado o disfarce do controle numa roupagem mais tecnicista nas práticas de cuidado do contemporâneo nos serviços públicos.

Ao mudar esse foco de atenção do nível terciário para a $\mathrm{AB}$, espera-se outra posição do usuário, oposta à dependência estrita ao hospital, por exemplo. Assim, a ênfase concedida à $\mathrm{AB}$ no sistema de saúde visa favorecer outras apropriações e consequências da categoria cuidado, em que destacamos uma direção distinta à do estrito controle ou cura de doença. Nessa via, com intuito de concretizar os princípios e diretrizes do SUS, que preconizam a autonomia e o protagonismo do usuário em seu processo de produção de saúde, cria-se a Política Nacional de Humanização (PNH) (Brasil, 2004), uma iniciativa direcionada às práticas de saúde, introduzindo a compreensão de que no ato de cuidar não deve prevalecer o cuidado técnico e fragmentado, valorizando-se um cuidado integral (Freire, 2015). Ao tema aqui exposto interessa destacar que, com a PNH, o cuidado na área da saúde ganha contornos favoráveis ao protagonismo do indivíduo diante do ato de cuidar.

Ou seja, há uma direção de trabalho, sobretudo para os profissionais da saúde na $A B$, que parece óbvia, 
entretanto, na prática, é um desafio: estabelecer um caminho metodológico que sustente uma política à efetivação de práticas clínicas que descolem a condição dependente-alienante de oferta de saúde à população, marca histórica das orientações das políticas nacionais de saúde. Segundo Freire (2015), há uma lacuna entre o que preconizam as diretrizes das práticas de humanização e o cuidado e sua real aplicabilidade no cotidiano de trabalho dos profissionais de saúde.

Para além das proposições presentes nas políticas oficiais propostas pelo MS, Contatore, Malfitano \& Barros (2017) desenvolveram uma discussão hermenêutica com a finalidade de identificar múltiplos e divergentes significados em torno do cuidado. Ao tratar o cuidado na atenção à saúde, os autores sublinham que estudos recentes "têm apresentado uma produção de conhecimento abrangente, complexa e diversa sobre o tema" (p. 557). Pautando-se em estudos anteriores, os autores propõem uma classificação das abordagens do cuidado: pragmática do cuidado, clínica ampliada, gerencial do cuidado, filosófica do cuidado, emancipadora do cuidado, política do cuidado, sociológica do cuidado e cultural do cuidado, resumidamente articuladas a seguir:

O que envolve ações "pragmáticas" que se voltem a respostas efetivas às doenças, porém sob uma clínica "ampliada e compartilhada", que respeite a cultura e a subjetividade de quem é cuidado; tendo, também, um viés "gerencial", o qual convida atores formais e informais para serem responsáveis pelo cuidado, por meio de uma compreensão "filosófica", que ressalta a necessidade permanente de reflexão sobre as bases epistemológicas da ação que se efetiva, com o objetivo de desenvolver uma prática "emancipadora", que visa à autonomia do sujeito e ao lugar tácito do cuidado, considerando, sempre, as vertentes "política, sociológica e cultural" que integram toda e qualquer prática social. Desta forma, o cuidado se complexifica, humaniza, e coloca, no centro da discussão, a pessoa. (Contatore, Malfitano, \& Barros, 2017, p. 560)

A discussão aprofundada dessa classificação extrapola nossos objetivos. Contudo destaca-se uma observação do estudo apontado: os autores concluem que a base técnico-científica sobre o cuidado "pouco atende as reais demandas das pessoas" (Contatore et al., 2017, p. 553), e defendem como encaminhamento uma abordagem sociológica do cuidado (Contatore, Malfitano. \& Barros, 2019).

Neste artigo, a via para a abordagem do cuidado não é sociológica, mas problematiza as "reais demandas das pessoas" cotejando-as com a abordagem ao cuidado ofertado na Unidade Básica de Saúde (UBS). Ao compartilhar com equipes multiprofissionais dilemas na oferta de ações de saúde aos usuários no cotidiano de UBS, nosso encaminhamento foi articular campos do conhecimento que têm seu exercício na $\mathrm{AB}$ - a psicanálise e a psicologia do trabalho - para discutir as incidências do cuidado à saúde (usuário) e na saúde (trabalhador).

Com a finalidade de apreender a produção acadêmica alinhada a esses campos de conhecimento, realizamos uma breve revisão de artigos disponíveis aos pesquisadores brasileiros pelo Portal de Periódicos da Coordenação de Aperfeiçoamento de Pessoal de Nível Superior (Capes), contemplando o período de 2014 a 2018. Adotou-se como marco temporal a publicação oficial Núcleos de Apoio à Saúde da Família (Nasf): ferramentas para a gestão e o para o trabalho cotidiano (Brasil, 2014). $\mathrm{Na}$ busca, os descritores utilizados foram: cuidado na saúde na atenção básica e psicanálise; e cuidado na saúde na atenção básica e psicologia do trabalho.

No que se refere ao descritor cuidado na saúde na atenção básica e psicanálise, não foi encontrado nenhum estudo que articule ou, ainda, que problematize a contribuição da metapsicologia à categoria do cuidado ofertado na AB. Ou seja, que se interesse por problematizar as incidências pulsionais nos objetivos de intervenção nesse nível de assistência. Cenário completamente distinto, quando consideramos o nível terciário com um significativo montante de trabalhos sobre configurações clínicas e os limites e alcances da clínica psicanalítica.

Na busca orientada pelo descritor cuidado na saúde na atenção básica e psicologia do trabalho, chamounos atenção a predominância de artigos engajados na discussão de diversas dimensões para qualificação do cuidado nas ações de saúde, tomando as equipes de saúde como alvos privilegiados. Contudo não encontramos um aprofundamento analítico sobre o entrelaçamento entre a saúde dos próprios trabalhadores e o exercício do cuidado, conforme os atributos que se almeja agregar às ações de saúde - direção à qual pretendemos avançar.

Partindo dessa constatação, o artigo discute o que seria o cuidado à saúde em uma perspectiva que considere o indivíduo em sua singularidade (campo pulsional) e em seu protagonismo (ação no campo social), e não em uma vertente assistencialista e dependente interrogando nas sessões seguintes: quais seriam as contribuições da psicanálise na atenção básica, quando desloca a singularidade de um plano empírico-pedagógicomoral para um campo pulsional? E, ainda, de que modo a articulação da singularidade à autonomia e ao protagonismo pode contribuir também ao trabalhador na saúde?

\section{Contribuições da psicanálise à categoria do cuidado}

Nosso interesse com a metapsicologia psicanalítica é, inicialmente, interrogar a contribuição desse campo do conhecimento à intervenção psíquica no nível da $\mathrm{AB}$, em que se agrupam diferentes profissionais a fim de promover saúde e evitar o aparecimento de condições clínicas indesejadas ao bem-estar, condições 
essas decorrentes de um cuidado não estrito ao corpo biológico, atravessando, então, as diferentes práticas ofertadas ao usuário.

Nessa perspectiva, o exercício do cuidado como modalidade aproximativa de atendimento ao usuário tem sido fortemente aplicado em prol de uma forma de relação orientada pelo cuidado assistencial e compartilhada por todos os profissionais indistintamente. Tal cenário tem seu apoio no princípio da integralidade que, como conceito mais amplo, segundo Pinheiro \& Guizardi (2013), se dá pela edificação de práticas profissionais cotidianas eficazes, como um ideal regulador, um devir. Nessa perspectiva, continua o autor, a integralidade é um conjunto de práticas e saberes que têm em sua essência o cuidado às pessoas como componente existencial que dá suporte, valoriza e busca soluções diante de processos de saúdeadoecimento de cada um que necessita dessa atenção.

A integralidade, como destaca Carnut (2017), é um princípio, porque se vale da perspectiva totalizadora do ser humano, e é uma diretriz por ter se tornado guia do processo de trabalho, sobretudo na atenção primária. Fato que também recolhemos a partir de nossa inserção profissional na RMSF, em que muitas vezes, no cotidiano à assistência, o cuidado à saúde foi apropriado e expresso como atitudes vinculadas à boa educação, respeito e consideração ao problema a ser solucionado. Em nossa avaliação, o exercício do cuidado como modalidade estrita de atendimento ao usuário pode ser utilizado para obter comportamentos e valores de saúde, de modo que, muitas vezes, as especificidades de cada área se diluem em prol de uma forma de relação orientada pelo cuidado assistencial compartilhada por todos os profissionais indistintamente.

Não que a forma positiva de direção ao outro não deva orientar as relações na saúde - não se trata disso certamente -, mas da necessária construção de uma especificidade teórico-metodológica que responda à categoria do cuidado nas diferentes ofertas de intervenção, em que a produção de um saber por parte do usuário possa se incluir de forma decidida, retirando-o de uma condição de completa submissão ao saber/cuidado do outro sobre si. Ou seja, uma via, como sublinha Carnut (2017), que valoriza a dimensão subjetiva do indivíduo enquanto expressão única, tal como problematiza a clínica ampliada enquanto clínica do sujeito.

A pedagogia no cuidado se articula à história da oferta de atenção à saúde da população, em que a caridade associada à religiosidade estabelece uma atitude de cuidado genérico ao sujeito, um dom para cuidar do outro (Foucault, 1963/1987). Portanto uma condição não profissionalizada, a outro despossuído, desse modo, carente e que tem seus efeitos até hoje no trato infantilizado do paciente. Nessa perspectiva, podemos encontrar na nomeação assistencial - que muitas vezes se desdobra em um adjetivo já impróprio entre aqueles que problematizam a oferta em saúde - o conceito de assistencialismo, um modo de cuidado que acaba por manter o indivíduo numa condição de usufruto, amarrado ao poder de quem lhe dá e resolve suas questões.

Um aspecto clínico fundamental dessas modalidades de abordagem de controle diz respeito ao recurso à sugestão, que tanto opera na perspectiva do dom ao outro com a finalidade de cura quanto na relação profissional saúde-usuário. Freud (1905/1987) sublinha a sugestão como elemento terapêutico fundamental a qualquer prática de cura, pois a incidência no campo anímico é um elemento essencial ao tratamento do corpo. Reitera o fato de psiconeuroses serem condições muito acessíveis às influências anímicas, mais do que qualquer medicação, sendo quadros curados mais pela personalidade do médico do que pelo medicamento, na medida em que, destaca o autor, é a personalidade do médico quem exerce influência psíquica. Nessa via, a nomeação "psicoterapia" pode se incluir em qualquer oferta terapêutica que utilize essa ferramenta para a meta de uma recuperação (mudança de atitude) do paciente.

$\mathrm{O}$ esclarecimento freudiano quanto à sugestão responde, em muito, a atualidade de diversas práticas ofertadas no campo da saúde, em que a personalidade do profissional, em relação com as condições do viver do usuário, é um elemento essencial à mudança almejada na direção dos preceitos de saúde. Assim, confiança, atenção e afeto positivo são recursos intencionalmente desenvolvidos pelos profissionais como ferramentas de cura associados, é claro, às ferramentas específicas de intervenção dos diferentes campos. Carnut (2017) esclarece que o acolhimento é outra estratégia que corrobora com a prática integral, em que o agasalhamento e o acalento são condições para o encontro permeado de contato e afeto.

Vale lembrar que o próprio Freud utilizou essa ferramenta em seus trabalhos pré-analíticos com a técnica da sugestão hipnótica, a psicoterapia por meio da distração, do exercício e da provocação de afetos mais oportunos (Freud, 1905/1987). Os limites dessas práticas com muitos pacientes e a fragilidade quanto à permanência dos resultados obtidos em outros, associados à experiência clínica de Freud com as histéricas da época, o colocaram diante de um novo método. Cito a característica desse novo método: "é o mais penetrante, o que chega mais longe, aquele pelo qual se consegue a transformação mais ampla do doente ... é o mais interessante, o único que nos ensina algo sobre a gênese e a interação dos fenômenos patológicos" (Freud, 1905/1987, pp. 243-244).

Para os interesses do artigo, a antítese entre a técnica da sugestão e a analítica nos serve tanto para apontar as incidências da sugestão em todas as práticas especializadas ofertadas como também para valorizar a especificidade da resposta analítica ao dispositivo da sugestão mediante a oferta de tratamento psíquico por psicólogos no campo da saúde pública.

A analogia que Freud faz com as artes a partir de Leonardo da Vinci põe em absoluta clareza a diferença 
de condução, per via di porre, com a pintura, em que se trata de depositar sobre a tela incolor partículas coloridas, e per via di levare, com a escultura, em que se trata de retirar da pedra tudo o que encobre a superfície da estátua nela contida (Freud, 1905/1987). A terapia analítica se orienta per via di levare, retirando o excesso para que a forma inerente da pedra se apresente, numa direção oposta às práticas de sugestão que seguiriam a via da pintura, acrescentando do externo ao que considera uma tela em branco.

E aqui temos outra consequência que norteia a clínica psicanalítica à restrição do uso de modalidades mediadas pela sugestão: a eliminação das manifestações patogênicas prescrita pelas abordagens que associam saúde a essa condição de ausência não significa eliminação do núcleo de pathos. Com efeito, a psicanálise se especifica entre as ofertas terapêuticas de cuidado, como uma modalidade de tratamento que consente ao campo do pathos, a fim de que um sujeito possa encontrar as palavras e os atos que transformem uma vivência patológica, excessiva e fora da norma em uma experiência psico-patho(s)-lógica, incluída e ordenada por um cuidar de si, ou seja, operar com seu pathos nas possibilidades de um viver. De modo algum é trabalho fácil e evidente, mas o único a se produzir enquanto terapêutica do pathos, que justifica a nomeação inconsciente na sua radicalidade e diferença ao campo das formações egoicas atravessadas pelos fatores simbólicos normatizantes.

O sentido de pathos é retomado por Berlink (2008) quando este sublinha sua derivação que comporta, para além de sofrimento, também a paixão e a passividade. O sujeito, constituído e coincidente com seu pathos, continua o autor, não é racional nem agente e senhor de suas ações. Nesse sentido: "quando pathos acontece, algo da ordem do excesso, da desmesura se põe em marcha sem que o eu possa se assenhorar desse acontecimento, a não ser como paciente" (Berlink, 2008, p. 18).

O paciente padece, pois, a causa de sua modificação, esclarece Berlink (2008), está em outra coisa que não ele mesmo, diferente do agente que encerra em si um poder de mover ou mudar. Podemos considerar isso como orientação às intervenções no campo psicanalítico, de um lugar de paciente submetido ao outro do conhecimento a um lugar de sujeito que, a partir do encontro com seu pathos, poderá estabelecer sua posição de agente de um viver em que lhe seja possível uma satisfação.

Nessa perspectiva, os dispositivos de tratamento psicanalítico prescindem da sugestão e de qualquer modalidade de reeducação emocional do paciente, em que a escuta jamais deve se orientar ao preenchimento do vazio, mas justamente promover a condição de relação do paciente com essa ausência. Aqui se tece, num segundo tempo, o efeito do encontro com esse pathos, uma condição por parte do sujeito de se fazer com a vida.

Desse modo, a novidade a partir da psicanálise é o deslocamento do cuidado para além do que apreende a consciência rotineira, convidando a um cuidado à produção do que Dunker (2013) nomeia por implicação: "um discurso que possa se interrogar eticamente sobre as formações de estranhamento com as quais se depara" (p. 71). Ou seja, a psicanálise traz a novidade de possibilitar a investigação do que escapa aos outros campos do cuidado à saúde: a dimensão do inconsciente, do não-sabido, do estranho, a singularidade.

A cura, como cuidado de si, voltada à singularidade, solicita recolhimento, retirada ou orientação para si (Dunker, 2011). Nessa perspectiva, não se trata de habilidades para olhar o outro, tampouco de uma relação dialógica ou dual necessária ao olhar de outro sobre si, mas da condição formativa de um profissional a favorecer a instauração de um olhar próprio a ser apropriado (pensado) pelo sujeito, num processo unilateral, ainda que necessariamente assistido, em presença, para se efetivar. O tratamento, assim, é necessariamente único e não redutível à aplicação técnica, pois a causa a ser tratada é da ordem de pathos, causa que motiva a instauração de um método de tratamento não químico ou moral, mas analítico e singular.

Sobre a especificidade desse tratamento psíquico, Quinet (2014) acentua a relevância dada à singularidade de cada fala, tanto no nível do enunciado quanto no da enunciação na direção de uma entrevistaencontro, tykhe, encontro do paciente com os efeitos de sua estrutura subjetiva. Ou seja, como destaca o autor, um encontro para detectar o pathos em que o sujeito se encontra, na diferença de entrevistas que são utilizadas para mostrar o acerto de um conhecimento e/ou reafirmar um sentido externo sobre o paciente que sofre. Lá, quem apresenta o caso é o próprio paciente: "é uma clínica do dito. Dar relevância a seu status de sujeito, fazendo com que ele próprio seja responsável pelo que conta, opõe-se aqui a considerar o paciente como objeto de observação, de asilo, de cuidados" (Quinet, 2014, p. 163).

Desse modo, apontamos uma especificidade do método psicanalítico, a diferença entre mal-estar (pathos) e sofrimento (doença), em que o mal-estar situa uma condição estrutural de perda necessária ao viver no campo da linguagem, impondo um não acesso à condição de completude suposta inicial do bebê humano e uma eterna busca de recuperação; e o sofrimento situa uma inoperância com esse mal-estar, acrescido da decepção do não encontro com a plenitude, impondo ao sujeito um viver passivo e submetido a outro que, no lugar de mestre, "cuida mal" ao anunciar o bem-estar pleno e não cumprir com a satisfação do imperativo de completude.

Essas especificidades metodológicas, associadas ao desenvolvimento científico de outras práticas psicoterápicas próximas ao paradigma objetivante da saúde, colocam a clínica psicanalítica, ainda hoje, diante da questão do reconhecimento de sua prática nas 
instituições de saúde. Entretanto também é fato que a incidência do campo pulsional perpassa a conclusão daqueles que problematizam os limites encontrados com as tentativas de cuidar do usuário, sobretudo nos casos com diagnósticos de difícil manejo clínico que incluem as recorrências sintomáticas muitas vezes incompreensíveis à lógica da saúde, interrogando as possibilidades de cura, como as adicções, os transtornos alimentares, as psicoses e a violência doméstica.

$\mathrm{O}$ que nos parece escapar aos profissionais nessas sintomatologias de difícil manejo clínico é a história de cada uma delas, que imprime e demanda um cuidado singular, incluindo o modo próprio com o qual cada usuário encaminha seu viver, não se reduzindo, assim, à patologia evidente que promove a busca pelo atendimento na saúde (Pinheiro, 2008).

É fato que todos os profissionais atuantes na saúde contemplam, em algum grau, a perspectiva aqui ilustrada por Pinheiro (2008); o problema é a solução que pretendem, ancorados no discurso científico de solução, por meio de técnicas ortopédicas afiliadas ao saber médico, as quais impõem a exclusão do campo do incompreensível, do sem sentido e impróprio ao exercício da saúde física e social, exatamente o campo que instaura a singularidade, propondo, para tanto, exercícios de controle e estratégias de cuidado que, muitas vezes, levam ao pior, amplificando o que esperavam curar.

A psicanálise, ao incluir o pathos como núcleo fundamental à apropriação de uma autonomia e da responsabilidade sobre si, soma a finalidade estabelecida por Mandú (2004) no que tange ao tratamento ao usuário, a ser considerado como um "sujeito ético-político com movimentos e potencialidades, e não como um objeto isolado, dado, passivo, subordinável à intervenção definida em bases unilaterais e à racionalidade uniforme e hierarquizante das teorias, técnicas, regras e interrelações" (pp. 671-672).

Essa orientação ao cuidado recoloca o termo, de uma ação a ser aplicada com vias a sanar um sofrimento que acomete um indivíduo por causas químicas, físicas e/ou sociais, para também uma oferta de apropriação do corpo e de si mesmo no mundo, a qual inclui a operação com o mal-estar existencial que pode se presentificar como sofrimento a partir do corpo biológico e/ou das interações sociais.

A relevância da dimensão subjetiva inerente ao processo saúde-doença que aqui nos interessa também incide sobre a atividade de trabalho, em que a fragmentação do processo de trabalho e a orientação cartesiana ao entendimento de metas e finalidades na saúde corroboram para condições desfavoráveis ao exercício das ações de saúde deslocadas dos paradigmas protocolares. Esse é o ponto que desenvolveremos a seguir, indicando reflexões para sua inclusão nas discussões sobre o cuidado em saúde.

\section{A categoria cuidado como uma atividade de trabalho: uma reflexão para a reconstrução das ações de saúde}

Com a criação e consolidação da estratégia SF e do Nasf, ampliou-se e diversificou-se a oferta de ações de saúde no território. Pautadas na construção de vínculos com os usuários, tais mudanças geram novas exigências aos seus trabalhadores e à organização do trabalho, com a transição da centralidade da figura do médico para a atuação em equipes multiprofissionais. Aliada a essas questões, constata-se a aposta na categoria cuidado como alternativa para a reconstrução das ações de saúde, de forma a transcender intervenções de cunho estritamente biologizantes e tecnicistas, que concedem ao usuário um lugar secundário na sua definição (Ayres, 2004). Diante desse cenário, esta seção almeja discutir a aplicabilidade da categoria cuidado às ações de saúde explorando a fecundidade de tratá-la como uma atividade de trabalho.

Como horizonte há a defesa da compreensão de que a assistência à saúde dos usuários está intimamente relacionada à conquista e ao fortalecimento da saúde dos próprios trabalhadores do SUS - não só os psicólogos, mas todos os trabalhadores implicados com as ações de saúde propostas. A fim de sustentar esse argumento, toma-se como ponto de partida a interrogação acerca do conceito de saúde, concedendo lugar destacado às reflexões do médico e filósofo Georges Canguilhem. $\mathrm{Na}$ avaliação de Ayres (2016), seu discurso possibilita a compreensão do que se faz e o que não se faz na Saúde Coletiva, além de ser fonte para pensar estratégias de aperfeiçoá-la.

Canguilhem construiu uma reflexão sobre a vida e a saúde tendo como ponto de partida a normatividade - instituição de novas normas -, própria do ser vivo e constitutiva da vida (Portocarrero, 2009). Assim, a saúde passa a ser entendida como a capacidade de criar novas normas, valores e modos de viver diante de infidelidades, variações e imprevistos inerentes à própria vida. $\mathrm{O}$ normal seria a instauração de novas normas, "que começa com o ser vivo, e com ele advém a diversidade" (Portocarrero, 2009, p. 129).

Recoloca-se, portanto, a questão da relação entre um organismo como ser vivo e seu meio: a saúde é produto do debate permanente com o meio e não implica somente em segurança contra os riscos, mas na capacidade de enfrentá-los (Caponi, 1997). Pode-se falar em saúde quando se tem os meios para enfrentar as dificuldades e compromissos, cuja conquista e ampliação é uma tarefa ao mesmo tempo individual e coletiva.

A qualidade que diferenciaria o estado da saúde do estado patológico (doença) seria a abertura a eventuais modificações, pois essa abertura estaria presente na saúde e ausente no estado patológico, conferindo à doença um caráter conservador. A saúde deficiente está associada a uma redução da capacidade normativa, uma limitação da tolerância e compensação das agressões do meio. 
As contribuições de Canguilhem como norteadores do trabalho em saúde exigiria uma apreensão da normatividade vital dos usuários (ou sua deficiência) diante das situações da vida para, a partir dela, operacionalizar a intervenção. Apoiar-se na normatividade vital dos usuários impede a objetivação e antecipação total dessas ações e favorece $a$ atenção às considerações psicanalíticas sobre o cuidado, discutidas anteriormente.

Nesses termos, a eficácia das ações de saúde demanda uma perspectiva muito mais compreensiva do que prescritiva (protocolar) por parte dos profissionais de saúde. Assim, defendemos que esse aspecto deve ser agregado e cotejado ao problematizar a categoria cuidado.

Outra questão ganha relevo: ponderando-se o encontro com o usuário como um encontro atravessado por dimensões parcialmente imprevisíveis e relacionadas à sua capacidade normativa, exercer essa postura compreensiva pressupõe que os trabalhadores exerçam, também eles, sua própria normatividade vital e criem normas de cuidado. Trata-se de um ciclo no qual a produção do cuidado à saúde dependeria também da conquista e do fortalecimento da saúde dos próprios trabalhadores, de sua capacidade normativa mediante as insuficiências protocolares.

Defender a saúde dos trabalhadores nos convoca a falar do trabalho, visto que ele envolve relações tanto entre os homens quanto entre eles e o meio onde trabalham e vivem. Pode-se afirmar que o trabalho é uma atividade que tem uma finalidade, mas também é o momento em "que se pode pôr em prática a capacidade humana de se reapropriar das situações e reinventá-las, instituindo novas regras e normas" (Brito, Athayde, \& Neves, 2003, p. 39). Assim, constitui-se um importante papel como operador de saúde.

Com efeito, a discussão do cuidado pode ser enriquecida tratando-o como uma atividade de trabalho, constructo teórico que aborda a demanda por renormatização e inventividade presentes nas situações de trabalho, somando-se o caráter não totalmente padronizável da vida e do trabalho. Além das contribuições da démarche da ergologia, atualmente existem diversas "teorias da atividade", entre as quais destacamos a ergonomia da atividade e correntes da psicologia do trabalho francesa, como a clínica da atividade (Athayde \& Zambroni-de-Souza, 2015).

Compreender o cuidado como uma atividade de trabalho permite colocar em evidência, numa primeira abordagem, a capacidade dos humanos de criar normas; além da geração de respostas originais, conhecimentos/ saberes no e sobre o trabalho mediante insuficiências e limites da tarefa prescrita em virtude de uma série de imprevistos inerentes às situações de trabalho (Athayde \& Zambroni-de-Souza, 2015).

Portanto apreender o cuidado como atividade de trabalho dá abertura a outras dimensões de análise. Dejours (2011) define o trabalho como um confronto com o real, "um real que se deixa conhecer por sua resistência a se submeter aos conhecimentos e às diferentes formas de saber-fazer" (pp. 434-435). No que diz respeito ao foco de problematização - o cuidado - agrega-se o confronto com a dimensão pathos, no ponto em que essa resistência pode se converter em psicopatologia, ou seja, atividade de trabalho desligada de sua potência de realização. Desse modo o confronto com o real do trabalho pode ser gerador de sofrimento e paralisação, ou motor que impulsiona o sujeito na busca de soluções para a atividade e, assim, para si mesmo.

Quando os trabalhadores conseguem ser normativos e extrapolar os limites do real por estratégias e pela mobilização da inteligência (Dejours, 2011), o sofrimento é direcionado ao rumo da afirmação da saúde, originando um "saber-fazer" onde antes não havia nenhum, enriquecendo potencialmente a organização do trabalho. Caso contrário, o sofrimento se inscreve "quando o confronto se torna intransponível e leva à repetição constante dos mesmos problemas, dos mesmos fracassos, tornando-se insuportável" (Dejours, 2011, pp. 434-435).

Reconhecer a atividade de trabalho operadora do cuidado também permite dar visibilidade ao sofrimento no trabalho em suas diversas nuances. Contudo, para que essa posição perante a categoria cuidado dirija um processo virtuoso de afirmação da saúde, com benefícios tanto para trabalhadores quanto para a organização do trabalho, é necessário garantir condições sociais favoráveis à passagem da contribuição individual ao trabalho para a dimensão coletiva.

Tal passagem se daria por meio da dinâmica do reconhecimento (Dejours, 2011), processada por meio de dois julgamentos do trabalho executado: o julgamento da utilidade (relativa à técnica, social e econômica) e o julgamento da beleza (qualidade do trabalho).

Se essa dinâmica obtém êxito, é possível registrar benefícios para a organização do trabalho com a invenção de novos modos de fazer que possam ser integrados ao coletivo de trabalho e institucionalizados. Para os trabalhadores implicados, o reconhecimento contribui para a afirmação de sua saúde (conforme a contribuição de Canguilhem) e para a construção do sentido no trabalho, na medida em que deixam de ser coadjuvantes do processo de trabalho.

Outro exemplo que responde a essa perspectiva é a contribuição de Oury (2009), problematizando a necessária abordagem coletiva ao cuidado de sujeitos submetidos ao excesso de pathos no viver, quando esclarece a função do coletivo na sua diferença a um grupo institucionalizado tecnocraticamente: "um sistema que permita a emergência de alguma coisa ... que ela não seja sufocada pelas tramas repressivas" (Oury, 2009, p. 73). Tramas que dizem respeito a uma imposição, um "é preciso fazer isso" a partir de normativas que excluem as possibilidades criacionistas de abordagem ao viver. Então o coletivo, como considerado pelo autor, seria um "espaço do dizer", dizer a ser constituído 
tanto no coletivo dos profissionais quanto na oferta coletiva de cuidado à saúde do usuário em que, assim, cada profissional ofertaria a contribuição de sua especificidade ao tratamento de pathos na sua vertente de excesso patológico.

Contudo tal dinâmica de trabalho pode ser ameaçada por questões de ordem política, ideológica e econômica. O Brasil presencia, desde 2016, uma reorganização das forças políticas conservadoras e um rápido fortalecimento de uma pauta de ação orientada para o aprofundamento da mercantilização dos direitos sociais brasileiros (Morosini, Fonseca, \& Lima, 2018), incluindo o direito à saúde. Um marco interessante nesse aspecto foi a reformulação da Política Nacional de Atenção Básica (Brasil, 2017), por exemplo, legitimando, assim, "a relativização da cobertura universal, a segmentação do acesso, a recomposição das equipes, a reorganização do processo de trabalho e a fragilização da coordenação nacional da política" (Morosini et al., 2018, p. 11).

Muitos autores já discutem as repercussões de tais mudanças legislativas para o usuário do SUS (Morosini et al., 2018; Ocké-Reis, 2017). Do ponto de vista do trabalho, entende-se que limites legais para gastos financeiros ou mesmo a ausência de investimentos associados à rigidez das metas de atendimento estabelecidas e à privatização da área da saúde configuram um quadro de precarização do emprego em saúde semelhante a outros setores de produção (Assunção \& Jackson-Filho, 2011).

Atentar-se a esse contexto desvela contradições entre as exigências das políticas de saúde, pautadas em preceitos preconizados pela categoria cuidado, e as condições ofertadas aos trabalhadores para o exercício do trabalho com impedimentos à normatividade vital, prejuízos à dinâmica do reconhecimento e aos efeitos positivos que daí podem decorrer, como a qualificação de reuniões de matriciamento ${ }^{2}$ e a construção de projetos terapêuticos singulares ${ }^{3}$.

\section{Considerações finais}

O artigo propôs, a partir de reflexões originadas numa experiência de inserção na RMSF, contribuir à análise da categoria cuidado, a fim de ofertar aos trabalhadores no campo e, sobretudo, aos psicólogos inseridos na $\mathrm{AB}$, uma ampliação ao escopo de trabalho. Desenvolve-se uma argumentação que concede outra extensão à (inter)subjetividade, sua incidência pulsional,

2 O matriciamento é uma estratégia que contribui para o cuidado integral, na medida em que proporciona o encontro entre equipes, atores $\mathrm{e}$ saberes, a fim de construir, de forma compartilhada, práticas de cuidado englobando, para além das questões de saúde, os determinantes sociais no processo de saúde e doença (Iglesias \& Avellar, 2016).

3 O Projeto Terapêutico Singular (PTS) é resultado de articulações de propostas e práticas de cuidado, seja visando um indivíduo ou um coletivo. Essas articulações advêm de discussões coletivas e interdisciplinares, com apoio matricial, se for o caso, e principalmente com a inclusão na construção do PTS do usuário ou coletivo em questão (Brasil, 2010). inerente ao trabalho em saúde, tanto na perspectiva do atendimento ao usuário quanto do trabalhador, ao introduzir a ótica das relações entre processos de trabalho e saúde.

No Brasil, a consolidação AB se apresenta como alternativa para superar a predominância de uma abordagem biologizante e curativa presente nas orientações das políticas nacionais de saúde. Aposta-se na categoria do cuidado como oportunidade para fazer surgir outra coisa que não estritamente controle ou cura de doença, ou seja, para trazer à cena os determinantes ao processo de apropriação de um viver que oriente condições de vida favoráveis ao encontro com a satisfação. Para tanto trata-se de fazer uso da particularidade nesse nível de intervenção, os usuários não estão alijados de sua capacidade de circular, como recurso de saúde, inclusive diferente de uma internação hospitalar e/ou cronicidade que impõem limitações à condução da própria vida.

Para isso a oferta multidisciplinar de saúde precisa encontrar sua via de intervenção na diferença aos modelos curativos-prescritivos à doença. Nessa perspectiva, a contribuição da psicanálise, ao orientar o tratamento de um sujeito pela inclusão de pathos, convida novas formas de abordagem ao usuário e, também, ao trabalhador da saúde.

Os desdobramentos das contribuições do conceito de saúde de Canguilhem permitem um ponto de convergência às diferentes aproximações - psicanálise e psicologia do trabalho e organizacional - da categoria cuidado desenvolvidas neste artigo. A sinalização da exigência de uma postura compreensiva nas ações de saúde em vez de prescritiva, acerca dos modos de vida do usuário, oferece a este outros destinos, a partir da escuta psicanalítica de um sujeito sobre seu processo saúde-doença e a partir de uma posição coletiva de inclusão da singularidade para as intervenções das especificidades profissionais nos processos de saúdedoença. Ao introduzir essas dimensões, o artigo espera contribuir ao fazer compreensivo dos profissionais de saúde, alimentando um círculo virtuoso no qual a capacidade normativa dos trabalhadores pode ser fortalecida na direção do aperfeiçoamento das ações de saúde.

Em outra frente, o reconhecimento da atividade de trabalho operadora do cuidado expande a atenção para além do usuário e introduz a normatividade vital, mobilizada pelos trabalhadores, aos debates sobre a formulação das ações de saúde, incorporando as formas de enfrentar o real do trabalho. Trata-se de um importante ponto de partida à problematização acerca das condições sociais favoráveis à passagem da contribuição individual ao trabalho para a dimensão coletiva, com benefícios tanto para trabalhadores quanto para a organização do trabalho, no sentido de superar ações exclusivamente assistencialistas e tutelares do usuário.

Com efeito, propomos a apropriação da atividade de trabalho sob a rubrica dos espaços coletivos de dizer, e 
não como regularidades institucionais para a confrontação e/ou conformação de ditos a serem aplicados a condutas dos usuários julgadas desajustadas. Desse modo, partindo da premissa de que o normal seria a instauração de novas normas ou, ainda, em interlocução com a psicanálise, a inscrição de uma forma própria de viver, a partir de um (bem) dizer-se, interrogar nessa perspectiva o cuidado no âmbito da atenção básica é colocar em relevo a potência do espaço coletivo quando articulado aos efeitos do campo pulsional para a atividade de trabalho, não apenas em relação ao usuário, mas também ao próprio trabalhador da saúde.

Por fim, as reflexões aqui desenvolvidas sublinham a importância do resgate das especificidades de cada campo de intervenção que se apropria da categoria do cuidado nas suas ações, se o horizonte for o desenvolvimento da responsabilidade do usuário em face de seu viver, a fim de proteger a categoria cuidado de uma apropriação generalizante e/ou superficial, que acaba por estabelecer ações estritamente assistencialistas. Portanto trata-se, neste artigo, de uma contribuição à tessitura de um problema, somando à complexidade do campo das intervenções na saúde pública, o que nos coloca a necessidade constante de desenvolvimentos futuros na direção de formas aprimoradas de escuta e encaminhamentos ao mal-estar manifestado pelos usuários e seus desdobramentos ao exercício do trabalho na saúde pública.

\title{
Health care: from citizen assistance to the autonomy of a subject
}

\begin{abstract}
This paper analyzes healthcare actions in Primary Health Care, questioning the predominance of offer and demand in healthcare model. In response, it marks the relevance of psychoanalysis in care that surpasses the citizen to be rightfully served, indicating the right to care for the subject in their singularity. Added to this perspective are the benefits of work psychology, in which the conquest and strengthening of the health of the workers themselves are necessary for the sustainability of care beyond the application of normative protocols. Thus, the inclusion of psychoanalysis and work psychology adds to the exercise of health care, broadening the perspectives of psychologists involved in primary healthcare beyond the level of a traditional offer of healthcare.
\end{abstract}

Keywords: psychology in health, psychoanalysis, primary health care, work activity, workers' health.

\section{Sur le soins de santé : de l'assistance au citoyen à l'autonomie du sujet}

Résumé: Cet article met en discussion la catégorie du soin dans les soins de santé primaires, interrogeant la prévalence d'une offre et d'une demande dans la vie assistancielle-généralisante. Celui-là met le point sur la relevance de la psychanalyse à un soin qui dépasse le citoyen qui attend un service de droit, signalant un soin au sujet dans sa singularité. On y ajoute les bénéfices du domaine de la psychologie du travail dont la conquête et la fortification de la santé des travailleurs euxmêmes se sont inscrites tel que des besoins à la durabilité d'une offre de soins, par ailleurs l'application des protocoles normalisateurs. Dans ce parcours, I'inclusion de la psychanalyse et de la psychologie du travail vient à s'ajouter dans l'exercice du soin dans la santé, en élargissant les perspectives de travail des psychologues liés aux soins primaires qui dépasse le niveau d'offre assistancielle.

Mots clés : psychologie dans la santé, psychanalyse, soin en santé, activité de travail, santé des travailleurs.

\section{Sobre el cuidado en la salud: de la asistencia al ciudadano a la autonomía de un sujeto}

Resumen: El artículo discute la categoría de cuidado referente a las acciones de salud en la atención primaria, interrogándose sobre la predominancia de oferta y de demanda en la vía asistencial universal. Como respuesta, destaca la relevancia del psicoanálisis con relación al cuidado que excede al ciudadano que espera por un servicio directo, en dirección a un derecho por un cuidado al sujeto en su singularidad. Se añaden a esa perspectiva los beneficios del campo de la psicología laboral, en la cual la conquista y el fortalecimiento de la salud de los propios trabajadores se inscriben como necesarias a la sostenibilidad de una oferta de cuidado, más allá de la aplicación de protocolos normativos. En esta vía, la inclusión del psicoanálisis y de la psicología laboral se agregan al ejercicio del cuidado en la salud, ampliando las perspectivas de la actuación de los psicólogos vinculados a la atención primaria, más allá del nivel de la oferta asistencial.

Palabras clave: psicología en la salud, psicoanálisis, cuidado en la salud, actividad laboral, salud de los trabajadores. 


\section{Referências}

Álvarez, C. V., \& García, J. H. V. (2011). El cuidado en enfermería: perspectiva fenomenológica. Hacia la Promoción de la Salud, 16(2), 175-89. Recuperado de http://bit.ly/39jc3B7

Asensi, F. D. (2013). Direito à saúde: práticas sociais reivindicatórias e sua efetivação. Curitiba, PR: Juruá.

Assunção, A. A., \& Jackson-Filho, J. M. (2011). Transformações do trabalho no setor saúde e condições para cuidar. In A. A. Assunção \& J. Brito (Orgs.), Trabalhar na saúde: experiências cotidianas e desafios para a gestão do trabalho e do emprego (pp. 45-65). Rio de Janeiro, RJ: Editora Fiocruz.

Athayde, M. R. C., \& Zambroni-de-Souza, P. (2015). Por uma ergopsicologia: uma caixa de ferramentas e pistas. In I. M. R. Taveira, A. C. Limongi-França, \& M. C. Ferreira (Orgs.), Qualidade de vida no trabalho: estudos e metodologias brasileiras (pp. 263-275). Curitiba, PR: CRV.

Ayres, J. R. C. M. (2004). O cuidado, os modos de ser (do) humano e as práticas de saúde. Saúde e Sociedade, 13(3), 16-29. Recuperado de http://bit.ly/2IfkjpN

Ayres, J. R. C. M. (2016). Georges Canguilhem e a construção do campo da Saúde Coletiva brasileira. Intelligere, 2(1), 139-55. Recuperado de http://bit.ly/2TuKH4a

Berlink, M. T. (2008). Psicopatologia fundamental. São Paulo, SP: Escuta.

Bertolozzi, M. R., \& Greco, R. M. (1996). As políticas de saúde no Brasil: reconstrução histórica e perspectivas atuais. Revista da Escola de Enfermagem da USP, 30(3), 380-398. Recuperado de http://bit.ly/38nrhn3

Brasil. (2004). Núcleo Técnico da Política Nacional de Humanização. Política Nacional de Humanização: HumanizaSUS. Brasília, DF: Ministério da Saúde. Recuperado de http://bit.ly/38eGSW1

Brasil. (2010). Secretaria de Atenção à Saúde. Núcleo Técnico da Política Nacional de Humanização. Acolhimento nas práticas de produção de saúde. Brasília, DF: Ministério da Saúde. Recuperado de http://bit.ly/39li3sS

Brasil. (2014). Secretaria de Atenção à Saúde. Departamento de Atenção Básica. Núcleo de Apoio à Saúde da Família, volume 1: ferramentas para a gestão e para o trabalho cotidiano (Cadernos de atenção básica, n. 39). Brasília, DF: Ministério da Saúde.

Brasil. (2017). Portaria $n^{\circ}$ 2.436, de 21 de setembro de 2017. Aprova a Política Nacional de Atenção Básica, estabelecendo a revisão de diretrizes para a organização da Atenção Básica, no âmbito do Sistema Único de Saúde (SUS). Brasília, DF: Ministério da Saúde. Recuperado de http://bit.ly/2VBB2vo

Bravo, M. I. S. (2008). Política de saúde no Brasil. Cuiabá, MT: Secretaria de Estado de Saúde de Mato Grosso.

Brito, J., Athayde, M., \& Neves, M. Y. (2003). Saúde, cadê você? Cadê você? In J. Brito, M. Neves, \& M. Athayde (Orgs.), Caderno de textos: programa de formação em saúde, gênero e trabalho nas escolas (pp. 23-40). João Pessoa, PB: Editora Universitária.
Caponi, S. (1997). Georges Canguilhem y el estatuto epistemológico del concepto de salud. História, Ciência, Saúde: Manguinhos, 4(2), 287-307. Recuperado de http://www.scielo.br/pdf/hcsm/v4n2/v4n2a05.pdf

Carnut, L. (2017). Cuidado, integralidade e atenção primária: articulação essencial para refletir sobre o setor saúde no Brasil. Saúde em Debate, 41(115), 1177-1186. Recuperado de http://bit.ly/2ThjbIsContatore, O. A., Malfitano, A. P. S., \& Barros, N. F. D. (2017). Os cuidados em saúde: ontologia, hermenêutica e teleologia. Interface: Comunicação, Saúde e Educação, 21(62), 553563. Recuperado de http://bit.ly/2wqRZOm

Contatore, O. A., Malfitano, A. P. S., \& Barros, N. F. D. (2019). Por uma sociologia do cuidado: reflexões para além do campo. Trabalho, Educação $e$ Saúde, 17(1), 1-23. Recuperado de http://www.scielo.br/ pdf/tes/v17n1/0102-6909-tes-17-1-e0017507.pdf

Dejours, C. (2011). Entre o sofrimento e a reapropriação: o sentido do trabalho. In S. Lancman \& L. I. Sznelwar (Orgs.), Christophe Dejours: da psicopatologia à psicodinâmica do trabalho (pp. 433-448). Rio de Janeiro, RJ: Editora Fiocruz.

Dunker, C. I. (2011). Estrutura e constituição da clínica psicanalítica: uma arqueologia das práticas de cura, psicoterapia e tratamento. São Paulo, SP: Annablume.

Dunker, C. I. (2013). Sobre a relação entre teoria e clínica em psicanálise. In C. I. L. Dunker, A psicose na criança: tempo, linguagem e sujeito (pp. 63-73). São Paulo, SP: Zagodoni.

Escorel, S., \& Teixeira, L. A. (2012). Histórias das políticas de saúde no Brasil de 1822 a 1963: do império ao desenvolvimentismo populista. In L. Giovanella, S. Escorel, L. V. C. Lobato, J. C. Noronha, \& A. I. Carvalho (Orgs.), Politicas e sistema de saúde no Brasil (pp. 279321). Rio de Janeiro, RJ: Editora Fiocruz.

Fertonani, H. P., Pires, D. E. P. D., Biff, D., \& Scherer, M. D. D. A. (2015). Modelo assistencial em saúde: conceitos e desafios para a atenção básica brasileira. Ciência \& Saúde Coletiva, 20(6), 1869-1878. Recuperado de http:// bit.ly/3crJZNW

Foucault, M. (1987). O nascimento da clínica. Rio de Janeiro, RJ: Forense Universitária. (Trabalho original publicado em 1963)

Foucault, M. (2002). A arqueologia do saber. Rio de Janeiro, RJ: Forense Universitária. (Trabalho original publicado em 1969)

Freire, M. A. B. (2015). As concepções de cuidado e a política nacional de humanização no cenário da enfermagem. Saúde \& Transformação Social, 6(3), 88-95. Recuperado de http://bit.ly/39k73fv

Freud, S. (1987). Sobre a psicoterapia. In Edição standard brasileira das obras psicológicas completas de Sigmund Freud (J. Salomão, trad., Vol. 7, pp. 239-254). Rio de Janeiro, RJ: Imago. (Trabalho original publicado em 1905) 
Iglesias, A., \& Avellar, L. Z. (2016). As contribuições dos psicólogos para o matriciamento em saúde mental. Ciência e Profissão, 36(2), 364-379. Recuperado de http://bit.ly/39ks4GL

Lobato, L. V. C., \& Giovanella, L. (2012). Sistemas de saúde: origens, componentes e dinâmica. In L. Giovanella, S. Escorel, L. V. C. Lobato, J. C. Noronha, \& A. I. Carvalho (Orgs.), Políticas e sistema de saúde no Brasil (pp. 89120). Rio de Janeiro, RJ: Editora Fiocruz.

Mandú, E. N. T. (2004). Intersubjetividade na qualificação do cuidado em saúde. Revista Latino-Americana de Enfermagem, 12(4), 665-675. doi: 10.1590/ S010411692004000400013

Marques, R. M., \& Mendes, Á. (2003). Atenção básica e Programa de Saúde da Família (PSF): novos rumos para a política de saúde e seu financiamento? Ciência \& Saúde Coletiva, 8(2), 403-415. Recuperado de http://bit. $1 \mathrm{y} / 3 \mathrm{crS} 0 \mathrm{Cj}$

Marta, C. B., \& Teixeira, E. R. (2016). Genealogia do cuidado na perspectiva foucaultiana. Revista de Pesquisa: Cuidado é Fundamental Online, 8(3), 47494756. Recuperado de http://bit.ly/2VBQFTD

Morosini, M. V. G. C., Fonseca, A. F., \& Lima, L. D. (2018). Política Nacional de Atenção Básica 2017: retrocessos e riscos para o Sistema Único de Saúde. Saúde em Debate, 42(116), 11-24. Recuperado de http://bit.ly/2uT7LkW

Nardi, H. C., \& Ramminger, T. (2012). Políticas públicas em saúde mental e trabalho: desafios políticos e epistemológicos. Psicologia: Ciência e Profissão, 32(2), 374-387. Recuperado de http://bit.ly/2IcPaDm
Ocké-Reis, C. O. (2017). Desafios da reforma sanitária na atual conjuntura histórica. Saúde em Debate, 41(113), 365-371. Recuperado em http://bit.ly/3alu2H5

Oury, J. (2009). O coletivo. São Paulo, SP: Aderaldo \& Rothschild.

Pinheiro, R. (2008). Cuidado em saúde. In I. B. Pereira (Org), Dicionário da educação profissional em saúde (pp. 110114). Rio de Janeiro, RJ: EPSJV.

Pinheiro, R., \& Guizardi, F. L. (2013). Cuidado e integralidade: por uma genealogia de saberes e práticas no cotidiano. In R. Pinheiro \& R. A. Mattos, Cuidado: as fronteiras da integralidade (pp. 23-38). Rio de Janeiro, RJ: Abrasco.

Portocarrero, V. (2009). As ciências da vida: de Canguilhem a Foucault. Rio de Janeiro, RJ: Editora Fiocruz.

Quinet, A. (2014). Teoria e clínica da psicose. Rio de Janeiro, RJ: Forense Universitária.

Ramos, E. M. B., \& Netto, E. B. M. (2017). Histórico do sistema normativo de saúde no Brasil: uma análise da construção do ordenamento jurídico da saúde pós-1988. Revista Debates, 11(1), 43-66. Recuperado de http://bit. 1y/3cr5QF8

Scherer, M. D. A., \& Menezes, E. L. (2016). Atenção primária à saúde: espaço potencial de criatividade. Tempus Actas de Saúde Coletiva, 10(3), 137-146. Recuperado de http:// bit.ly/2TgyGAu
Recebido: 08/08/2018

Revisado: 28/10/2019

Aprovado: 28/12/2019 